\title{
Association of EEG, MRI, and regional blood flow biomarkers is predictive of prodromal Alzheimer's disease
}

\section{Davide Vito Moretti}

IRCCS S Giovanni di Dio Fatebenefratelli, Brescia, Italy
Correspondence: Davide Vito Moretti IRCCS S Giovanni di Dio Fatebenefratelli via Pilastroni, 4 25I25 Brescia, Italy

Tel +39030 350 I597

$\mathrm{Fax}+390303533513$

Email davide.moretti@afar.it
This article was published in the following Dove Press journal:

Neuropsychiatric Disease and Treatment

27 October 2015

Number of times this article has been viewed

Background: Thinning in the temporoparietal cortex, hippocampal atrophy, and a lower regional blood perfusion is connected with prodromal stage of Alzheimer's disease (AD). Of note, an increase of electroencephalography (EEG) upper/low alpha frequency power ratio has also been associated with these major landmarks of prodromal AD.

Methods: Clinical and neuropsychological assessment, EEG recording, and high-resolution three-dimensional magnetic resonance imaging were done in 74 grown up subjects with mild cognitive impairment. This information was gathered and has been assessed 3 years postliminary. EEG recording and perfusion single-photon emission computed tomography assessment was done in 27 subjects. Alpha3/alpha2 frequency power ratio, including cortical thickness, was figured for every subject. Contrasts in cortical thickness among the groups were assessed. Pearson's $r$ relationship coefficient was utilized to evaluate the quality of the relationship between cortical thinning, brain perfusion, and EEG markers.

Results: The higher alpha3/alpha2 frequency power ratio group corresponded with more prominent cortical decay and a lower perfusional rate in the temporoparietal cortex. In a subsequent meetup after 3 years, these patients had AD.

Conclusion: High EEG upper/low alpha power ratio was connected with cortical diminishing and lower perfusion in the temporoparietal brain area. The increase in EEG upper/low alpha frequency power ratio could be helpful in recognizing people in danger of conversion to $\mathrm{AD}$ dementia and this may be quality information in connection with clinical assessment.

Keywords: electroencephalography, mild cognitive impairment, hippocampal volume, brain rhythms, biomarkers

\section{Introduction}

According to current investigation criteria, it is becoming clear that the mix of different biomarkers is an improvement for a privileged and early detection of Alzheimer's disease (AD). ${ }^{1,2}$ To date, the most discussed are endorsed biomarkers, Abeta42 and tau protein, in the cerebrospinal fluid, glucose hypometabolism measured by fluorodeoxyglucose positron release tomography (18F-FDG PET), decay of hippocampal volume (HV) on magnetic resonance imaging (MRI), and weight of amyloid burden measured by amyloid imaging with PET. ${ }^{3-16}$ Regardless, a couple of points remain. The late biomarkers are important in detecting subjects with neurodegenerative problem who are at high risk of it changing into dementia; in any case, they do not have a tried and true specificity that permits an obvious completion of the different subtypes of dementia. Of note, in neurodegenerative diseases such as AD or other dementias, the brain structure modifies many years before clinical appearances. Late MRI studies have demonstrated that a sweeping neural framework is adjusted in subjects with prodromal AD. ${ }^{17-22}$ 
In particular, subjects with scholarly rot exhibit early rot and loss of dim matter in cortical-specific zones, ${ }^{18,20}$ in particular, the parietal and precuneus areas as well as medial temporal and hippocampal cortices. In the sensible edge of the joining of biomarkers for an early and significantly farsighted discovery, the electroencephalography (EEG) could be a strong tool. ${ }^{23}$ Certainly, it is comprehensively recognized that the cerebral EEG rhythms reflect the essential brain framework activity. ${ }^{24}$ As a result, the changes in EEG rhythms could be an early sign of AD. ${ }^{25-28}$ Past studies have convincingly displayed that there are thalamo-cortical and cortico-cortical fragments that contribute to the generation of cortical alpha rhythms. Of late, it has been discovered the increase of high alpha/ low alpha ratio is a strong EEG marker of hippocampal rot. ${ }^{29,30}$ In addition, the augmentation in the alpha3/alpha2 (a3/a2) power ratio extent has been indicated to be insightful to the progress of patients with mild cognitive impairment (MCI) to AD, however, not to non-AD dementia. ${ }^{31}$ The same augmentation of a $3 / \mathrm{a} 2$ power ratio was found to be connected with hippocampal rot in subjects with $\mathrm{AD} .{ }^{32-38}$ On the other hand, subjects with higher a3/a2 power proportion showed a consistent example toward a lower regional blood perfusion than the low a3/a2 group. ${ }^{39}$

This study inquired about the relationship between MRI and single-photon emission computed tomography (SPECT) with regard to the MCI group of subjects with higher a3/a2 power ratio. Results show that the higher a3/a2 power ratio was associated with both MRI and SPECT prodromal AD designs. Finally, this group of subjects exhibits an adjustment in $\mathrm{AD}$ following a 3-year postliminary.

\section{Materials and methods Subjects}

Seventy-four subjects with MCI were recruited from the Memory Clinic of the Scientific Institute for Research and Care (IRCCS) of Alzheimer's and psychiatric diseases,
"Fatebenefratelli", in Brescia, Italy. All experimental and study protocols were approved by the local ethics committee. Informed consent was obtained from all participants or their caregivers, as per the recommendation of the Code of Ethics of the World Medical Association (Declaration of Helsinki).

\section{Diagnostic criteria}

Patients were chosen from a prospective study of cognitive impairment (the Translational Outpatient Memory Clinic study) conducted in the outpatient office of the National Institute for the Research and Care of Alzheimer's Disease (IRCCS, Istituto Centro San Giovanni di Dio Fatebenefratelli, Brescia, Italy). Patients were appraised with a progression of institutionalized demonstrative and seriousness instruments, including the Mini-Mental State Examination (MMSE),${ }^{40}$ the Clinical Dementia Rating Scale, ${ }^{41}$ the Hachinski Ischemic Scale, ${ }^{30}$ the instrumental activities of daily living (IADL), the basic activities of daily living (BADL), ${ }^{42-45}$ and a complete neuropsychological evaluation, institutionalized on Italian population. ${ }^{46,47}$ Likewise, patients experienced analytic neuroimaging methods (MRI) and research facility testing to preclude different reasons for cognitive deterioration. Inclusion criteria of the study were as follows: 1) grumbling by the patient or report by a relative regarding memory or other intellectual impairments; 2) MMSE score of 24-28/30; ${ }^{46}$ and 3 ) saving of IADL and BADL. Prohibition criteria were any of the accompanying: 1) patients aged 90 years older (no base age to take an interest in the study), 2 ) history or neurological indications of real stroke, 3) any psychiatric disease, 4) epilepsy, 5) utilization of psychoactive medications, including acetylcholinesterase inhibitors or different medications upgrading mind intellectual capacities or biasing EEG activity, 6) chronic systemic diseases such as diabetes, or 7) commotive traumatic brain injuries. ${ }^{1,44,45}$ All subjects were right-handed. Demographic and psychological components of the subjects in this study are given in Table 1.

Table I Demographic and cognitive characteristics of the whole sample, disaggregated for increased levels of a3/a2 numbers denote mean \pm standard deviation, number and (range)

\begin{tabular}{|c|c|c|c|c|}
\hline & \multicolumn{4}{|l|}{ a3/a2 } \\
\hline & High & Middle & Low & $\overline{P \text {-value }}$ \\
\hline \multicolumn{5}{|c|}{ Demographic and clinical features } \\
\hline Number of subjects & 18 & 38 & 18 & - \\
\hline Age (years) & $70.4 \mathrm{I}(60-85)$ & $68.4 \mid(52-83)$ & $70.4 \mid(57-80)$ & 0.55 \\
\hline Sex, female & $13(\%)$ & $24(\%)$ & $14(\%)$ & 0.51 \\
\hline Education (years) & $6.61(4-18)$ & $7.61(3-17)$ & $8.31(3-18)$ & 0.42 \\
\hline Mini mental state exam & $27.11(23-29)$ & $27.4 \mathrm{I}(24-30)$ & $26.91(23-30)$ & 0.46 \\
\hline $\mathrm{a} 3 / \mathrm{a} 2$ & $1.29(1.17-1.52)$ & $1.08(1-1.16)$ & $0.91(0.77-0.98)$ & 0.000 \\
\hline
\end{tabular}

Notes: $P$ denotes significance on ANOVA. Bold text denotes statistically significant values. Abbreviations: ANOVA, analysis of variance; a3, alpha3; a2, alpha2. 
There were no factually huge contrasts in age, sexual orientation, or instruction among the patients gathered in this study.

\section{Follow-up analysis}

Table 2 demonstrates the sociodemographical components of three groups of patients, which were acquired by the result of following 3 years of postliminary: 1) patients with MCI who did not change over to any dementia, 2) patients with $\mathrm{MCI}$ who changed over in $\mathrm{AD}$, and 3) patients with MCI who changed over to dementia other than AD (frontotemporal dementia range, vascular dementia, or Lewy body dementia).

\section{EEG recordings}

The EEG was recorded from 19 locales by utilizing electrodes set as a part of an elastic cap (Electro-Cap International, Inc. Eaton, $\mathrm{OH}, \mathrm{USA}$ ) and situated by 10-20 global frameworks (Fp1, Fp2, F7, F3, Fz, F4, F8, T3, C3, Cz, C4, T4, T5, P3, $\mathrm{Pz}, \mathrm{P} 4, \mathrm{~T} 6, \mathrm{O} 1$, and $\mathrm{O} 2$ ). The patients were told to sit with their eyes shut and relax; they were continually checked by an operator. The ground electrode was set before Fz. The left and right mastoids served as the reference for all terminals. The recordings were utilized to re-reference the scalp recordings to the common average. Re-referencing was done preceding the EEG artifacts identification and examination. Information were recorded with a band-pass filter of $0.3-70 \mathrm{~Hz}$ and digitized at an inspecting rate of $250 \mathrm{~Hz}$ (BrainAmp, Brain Products, Munich, Germany). Terminal skin impedance was situated underneath $5 \mathrm{kHz}$. Horizontal and vertical eye movements were recognized by the electrooculogram. ${ }^{4-52}$ The subjects endured the recording for 5 minutes with their eyes shut. EEG information was then broke down and divided off-line in successive periods of 2 seconds with a frequency resolution of $0.5 \mathrm{~Hz}$. The average number of periods analyzed was 140, ranging from 130 to 150 . The epochs with ocular, muscular, and different sorts of artifacts were tossed by two expert electroencephalographists. ${ }^{27}$ The spectral power we got is an estimation of a collapsed spectrum throughout the scalp electrodes. Along these lines, the contribution of the muscular artifacts is emphatically lessened. In addition, two talented electroencephalographists checked the EEG traces independently.

\section{Analysis of individual frequency bands}

A digitalized fast Fourier transform power spectrum analysis (Welch technique, Hanning windowing function, no phase shift) processed the power density of EEG rhythms (ranging from 2 to $45 \mathrm{~Hz}$ ) with a $0.5 \mathrm{~Hz}$ frequency resolution. Two principal frequencies (the theta/alpha transition frequency $[\mathrm{TF}]$ and the individual alpha frequency [IAF] peak) were chosen consistently with scientific guidelines. ${ }^{28,29}$ IAF and TF were recorded for every subject in this study. These anchor frequencies were computed on the whole scalp averaged power spectra. This "collapsed strategy", being a kind of standardized global field power, takes into consideration the recognizable proof of a reliable and stationary IAF. A large body of literature has convincingly demonstrated that the IAF is extremely robust in resting condition EEG recording, ${ }^{52-61}$ even if more alert has been recommended when the study subjects need to perform some particular active tasks. ${ }^{62}$ The TF marks the frequency of transition between the theta and alpha rhythms and is considered the frequency at which the theta and alpha spectra cross. TF was processed as the base power in the alpha recurrence range; following our EEG recordings were performed at rest. The IAF represents the frequency with the most extreme power top inside of the amplified alpha range (5-14 Hz). In light of TF and IAF, we assessed the frequency band range for every subject as takes after: delta from TF-4 to TF-2, theta from TF-2 to TF, low alpha band (alpha1 [a1] and a2) from TF to IAF, and high alpha band (or a3) from IAF to IAF +2 . The a1 and a2 bands were processed for every subject as follows: a1 from TF to the midpoint of the TF-IAF range, and a2 from this midpoint to the IAF crest. The mean frequency range registered in MCI subjects considered on average are delta $2.9-4.9 \mathrm{~Hz}$, theta

Table 2 ANOVA results of demographic variables, ie, age, education, MMSE score, and a3/a2 ratio

\begin{tabular}{llllll}
\hline & MCI cohort & MCI nonconverters & MCI AD converters & MCI non-AD converters & P-value (ANOVA) \\
\hline Number of subjects (F/M) & $74(46 \mathrm{~F} / 28 \mathrm{M})$ & $42(30 \mathrm{~F} / \mathrm{I} 4 \mathrm{M})$ & $18(\mathrm{IOF} / 8 \mathrm{M})$ & $14(7 \mathrm{~F} / 7 \mathrm{M})$ & \\
Age (years) & $69.7 \pm 2.3$ & $69.4 \pm 4.1$ & $71.8 \pm 5.7$ & $70.1 \pm 3.9$ & 0.1 \\
Education (years) & $7.4 \pm 0.8$ & $7.3 \pm 2.5$ & $8.4 \pm 3.1$ & $8.8 \pm 4.6$ & 0.4 \\
MMSE & $26.8 \pm 1.4$ & $27.2 \pm 1.4$ & $25.7 \pm 1.5$ & $26.8 \pm 1.8$ & $0.00 \mathrm{I}$ \\
a3/a2 ratio & $1.15 \pm 0.2$ & $1.14 \pm 0.3$ & $1.26 \pm 0.5$ & $1.03 \pm 0.7$ & 0.02 \\
\hline
\end{tabular}

Notes: The values are all intended at baseline. Data are presented as mean \pm SD.

Abbreviations: ANOVA, analysis of variance; MMSE, Mini-Mental State Examination; a3, alpha3; a2, alpha2; MCl, mild cognitive impairment; AD, Alzheimer's disease; $\mathrm{F}$, female, M, male. 
4.9-6.9 Hz, a1 6.9-8.9 Hz, a2 8.9-10.9 Hz, and a3 10. At long last, in the frequency bands decided on an individual premise, we registered the relative power spectra for every subject. The relative power density for every frequency band was figured as the proportion between the absolute power and the mean power density from 2 to $45 \mathrm{~Hz}$. The a3/a2 frequency power ratio was figured in all subjects and three groups were acquired by tertile estimations of a3/a2: low (a3/a2<1), middle $(1<\mathrm{a} 3 / \mathrm{a} 2<1.16)$, and high $(\mathrm{a} 3 / \mathrm{a} 2>1.17)$. The tertile division permits an adjusted distribution of the sample in study with the benefit of keeping away from the extreme values in the statistical examination. The three groups of MCI have been demonstrated in past studies to appear different among each other. Specifically, the high a3/a2 EEG power proportion $\mathrm{MCI}$ group is at significant danger to change over to $\mathrm{AD}^{31-44}$ contrasted with the other a3/a2 power ratio $\mathrm{MCI}$ groups. Also, we used this group subdivision for homogeneity and equivalence with the past studies.

\section{MRI scans}

For every subject, a high-resolution sagittal T1-weighted volumetric MRI output was procured at the Neuroradiology Unit of the "Città di Brescia" Hospital, Brescia, by utilizing a 1.0 T Philips Gyroscan scanner with a gradient echo three-dimensional procedure: $\mathrm{TR}=20 \mathrm{~ms}, \mathrm{TE}=5 \mathrm{~ms}$, flip angle $=30^{\circ}$, field of perspective $=220 \mathrm{~mm}$, securing grid $=256 \times 256 \mathrm{~mm}$, and cut thickness $=1.3 \mathrm{~mm}$.

\section{Cortical thickness estimation steps}

Cortical thickness estimations for 74 patients with MCI were made utilizing a completely automated MRI-based investigation system: FreeSurfer v5.1.0, an arrangement of software instruments for the investigation of cortical and subcortical brain structures. Quickly, in the cortical surface stream, the models of the limit between white matter and cortical gray matter (CGM), and also the pial surface, were constructed. At the point when these surfaces are known, a mixed bag of anatomical measures gets the opportunity to be possible, including cortical thickness, surface region, curvature, and surface normal at each point on the cortex. ${ }^{62,63}$

\section{Single-subject investigation}

For every subject, the T1-weighted, anatomical 3D MRI dataset were changed over from Dicom design into.mgz file position, intensity differences were amended, and a standardized intensity picture was made. The volume was registered with the Talairach atlas through a relative enlistment. Next, the skull was stripped utilizing a deformable format model, ${ }^{64}$ and extracerebral voxels were uprooted. The intensity standardized, skull-stripped picture was then worked on by a division system in view of the geometric structure of the gray-white interface. Voxels were named white or gray matter, and slicing planes were chosen to partition the hemispheres from one another. A white matter surface was then produced for every hemisphere by tiling the outside of the white matter mass for that hemisphere. Cortical thickness estimations were done by computing the separation between those surfaces (white and pial surfaces) at each of $\sim 160,000$ points on the hemispheres over the cortical mantle. ${ }^{65}$

\section{Group analysis}

Keeping in mind the end goal to relate and look at anatomical elements crosswise over subjects, it was important to build up a mapping that determines a kind of correspondence between every area in one cerebrum and comparing the area in another. In this way, the pial surface of an individual subject was expanded to focus the huge scale collapsing examples of the cortex, and in this way changed into a circle to minimize metric contortion. The collapsing examples of the individual were then adjusted to a normal collapsing example utilizing a high-determination surface-based averaging. Thickness measures were mapped to the swelled surface of every member's cerebrum reproduction, permitting representation of information over the whole cortical surface. Lastly, cortical thickness was smoothed with a $20 \mathrm{~mm}$ full width at half-stature Gaussian portion to decrease neighborhood varieties in the estimations for further examination. ${ }^{66-71}$

\section{Statistical analysis}

Contrasts between groups in sociodemographic and neuropsychological components were investigated utilizing SPSS software Version 13.0 (SPSS, Chicago, IL, USA) performing an analysis of variance (ANOVA) for continuous variables and paired $\chi^{2}$ test for dichotomous variables. For continuous variables, post hoc pairwise examinations among groups were performed with the Games-Howell or Bonferroni tests, contingent upon homogeneity of difference tried with Levene's test. Concerning the neuroimaging examination, the Qdec interface in FreeSurfer programming was utilized. A vertex-by-vertex examination was completed performing a general linear model to dissect whether any distinction in mean cortical thickness existed between groups (low: a3/a2 $<1 \mu \mathrm{V} 2$; center: $1<\mathrm{a} 3 / \mathrm{a} 2<1.16 \mu \mathrm{V} 2$; high: a3/a2 $>1.17 \mu \mathrm{V} 2$ ). The accompanying matches were completed as follows: high versus low, high versus middle, and middle versus low. Age, sex, instruction, global cognitive 
level (MMSE score), and white matter hyperintensities were presented as covariates in the examination to abstain from frustrating variables. We initially attempted to apply a proper Bonferroni numerous correlation revision in our examination (at $P<0.05$ corrected). However, no $P$-value was calculated after this revision. In this way, we decided to set a more restrictive limit (than $P<0.05$ rectified) at $P<0.001$ uncorrected for multiple comparisons. Besides, we considered the clusters as noteworthy if they were equivalent to or $>30 \mathrm{~mm}^{2}$. Lastly, a surface map was created to show the outcomes on a normalized brain. For illustrative purposes, significance was thresholded to a $P$-estimation of $<0.01$ uncorrected for multiple matches.

\section{Statistical follow-up analysis}

To begin with, one-way ANOVAs were performed keeping in mind the end goal to confirm that a3/a2 relative power ratio was altogether diverse among groups. At long last, a discriminant factor analysis was performed to check if the same critical variables could be helpful in separating subjects and could have a diagnostic meaning. The model was assembled as follows: variable choice was finished with a stepwise technique, tolerance was set to 0.01 , and $F$ to enter to 1.0 .

\section{SPECT scan}

Twenty-seven patients and 17 ordinary controls experienced SPECT check in the nuclear medicine unit of the Ospedali Riuniti Hospital, Bergamo. Every subject got an intravenous infusion of $925 \mathrm{MBq}$ of technetium-99m ethyl cysteinate dimer (99mTc-ECD) in resting condition, lying recumbent with eyes shut in a calm, faintly lit room. Forty minutes to an hour after infusion, cerebrum SPECT was performed utilizing a double-head pivoting gamma camera (GE Elscint Helix) outfitted with low vitality high determination, parallel opening collimators. A $128 \times 128$ pixel framework, zoom $=1.5$, was utilized for picture securing with 120 perspectives over a $360^{\circ}$ circle (in $3^{\circ}$ stages) with a pixel size and a cut thickness of $2.94 \mathrm{~mm}$. Butterworth separated back projection (order $=7$, cutoff $=0.45$ cycles $/ \mathrm{cm}$ ) was utilized for picture remaking, and weakening redress was performed utilizing Chang's system (lessening coefficient $=0.11 / \mathrm{cm}$ ). Pictures were traded in DICOM design.

\section{SPECT processing method}

To accomplish an exact standardization, we created a studyspecific SPECT format utilizing both SPECT and MR sweeps of all patients and typical controls under study following a strategy portrayed in subtle element somewhere else. ${ }^{72}$ Quickly, we made a redid superior quality MR layout, we changed over SPECT sweeps to Analyze configuration utilizing MRIcro (Columbia, SC, USA), and we coregistered them to their individual MR filters with SPM2 (SPM, Statistical Parametric Mapping, form 2; Functional Imaging Laboratory, London, England). We standardized each MR to the altered MR layout through a nonlinear change (cutoff $25 \mathrm{~mm}$ ) and applied the normalization parameters to the coregistered SPECT. We obtained the customized SPECT template as the mean of all the latter normalized SPECT images. The creation of a study-specific template allows for better normalization since it accounts for low uptake in ventricular structures and cortical hypoperfusion effects frequently present in elderly patients. The regions of interest (ROI), decided for perfusion investigations in every hemisphere from the Pick atlas by a subroutine executed on SPM2, were as follows: the thalamus, the hippocampal-amygdalar complex, frontal, parietal, and temporal lobes. ${ }^{72}$

\section{SPECT statistical analysis}

Every single factual analysis was performed utilizing SPSS programming Version 13.0. We explored the essentialness of the contrast between the two groups (MCI at low and at high hazard to create risk to develop AD) in sociodemographical, clinical, and intellectual components utilizing the $\chi^{2}$ test for all out variables (sex and ApoE carriers), and Student's independent $t$-test for continuous variables (volumetric, perfusion elements, and EEG frequencies). In all cases, we set the centrality limit at $P<0.05$. Since local SPECT outputs were coregistered to their individual MR pictures, and the study-specific SPECT layout was coregistered to the superior quality MR format, all the standardized SPECT and MR pictures utilized for the factual examination were coregistered to the SPM standard anatomical space. Pearson's $r$ correlations were surveyed between the chosen perfusion ROI (regarding age adjusted $\mathrm{W}$-scores) and the obtained EEG frequencies in both groups.

\section{Results}

\section{Magnetic resonance imaging}

Table 1 shows that the sociodemographic and neuropsychological issues of MCI subgroups are characterized by the tertile estimations of a3/a2 power ratio. The ANOVA examination demonstrated that there were no factually noteworthy contrasts between information gathered that matched for age, sex, white matter hyperintensities load, instruction, or mean cognitive level. 


\section{Pattern of cortical thickness between groups}

i) High versus low: when contrasted with subjects with low a3/a2, patients with high a3/a2 power ratio show diminishing in the respective superiotemporal, supramarginal, and precuneus cortices, in the right inferior parietal cortex, and in the insular cortex. The total volume of the CGM lessening in the high a3/a2 group contrasted with the low a3/a2 power ratio group was $471 \mathrm{~mm}^{2}$ (Figure 1).

ii) High versus middle: the same group demonstrated a comparative, however, less wide example of cortical atrophy when contrasted with the middle a3/a2 group: the districts of decay were situated in the left supramarginal gyrus, left precuneus, and postcentral cortex. The aggregate CGM diminishment in the high a3/a2 group contrasted with the middle a3/a2 group was $160 \mathrm{~mm}^{2}$ (Figure 2). At the point when the high group was contrasted with the low group, the aggregate degree of cortical diminishing $\left(471 \mathrm{~mm}^{2}\right)$ was $34 \%$ higher than in the examination of the high group to the middle group $\left(160 \mathrm{~mm}^{2}\right)$. No areas of major cortical decay were found in groups with middle or low a3/a2 frequency power ratio when contrasted with the high a3/a2 frequency power ratio subjects' cluster. No noteworthy cortical thickness contrasts were found between middle and low a3/a2 power ratio groups.

\section{SPECT}

Twenty-seven MCI patients were enlisted for the present study and delegated at high hazard (with the a3/a2 EEG power ratio as $>1.17 ; \mathrm{N}=13$ ) or at low hazard (with the a3/a2 EEG power ratio $<1.17 ; \mathrm{N}=14$ ) to develop $\mathrm{AD}$. The two groups were comparative for age $(P=0.56)$, instruction in years ( $P=0.87)$, sex $(P=0.17)$, ApoE genotype $(P=0.15)$, MMSE scores $(P=0.31)$, and white matter injuries load $(P=0.88)$. Figure 3 demonstrates that the visual rating size of the SPECT examines the illustration of typical control, MCI with low risk to change over to $\mathrm{AD}$, and $\mathrm{MCI}$ with high hazard to change over to AD. ANOVA results demonstrate that the chosen cutoff was viable in recognizing two unique groups: patients with high hazard to create $\mathrm{AD}$ indicate essentially higher a3/a2 power ratio than patients with low risk $(P=0.0001)$. Also, a control examination was performed on the single frequencies. The outcomes demonstrate that the increment of a3/a2 frequency power ratio was because of both increment of a3 $(P=0.001)$ and reduction of a2 $(P=0.0001)$ and not to the change of a solitary frequency band. This control examination was performed in light of the fact that the change of a single-frequency band could be because of chance; however, this was not the situation. Of note, no distinctions were found for beta 1, beta 2, gamma, theta EEG bands, or theta/gamma frequency power ratio (all $P>0.11$ ). In spite of the fact that the mean perfusion in all the chosen ROIs was comparable between groups (all $P>0.38$ ), in the group with high a3/a2

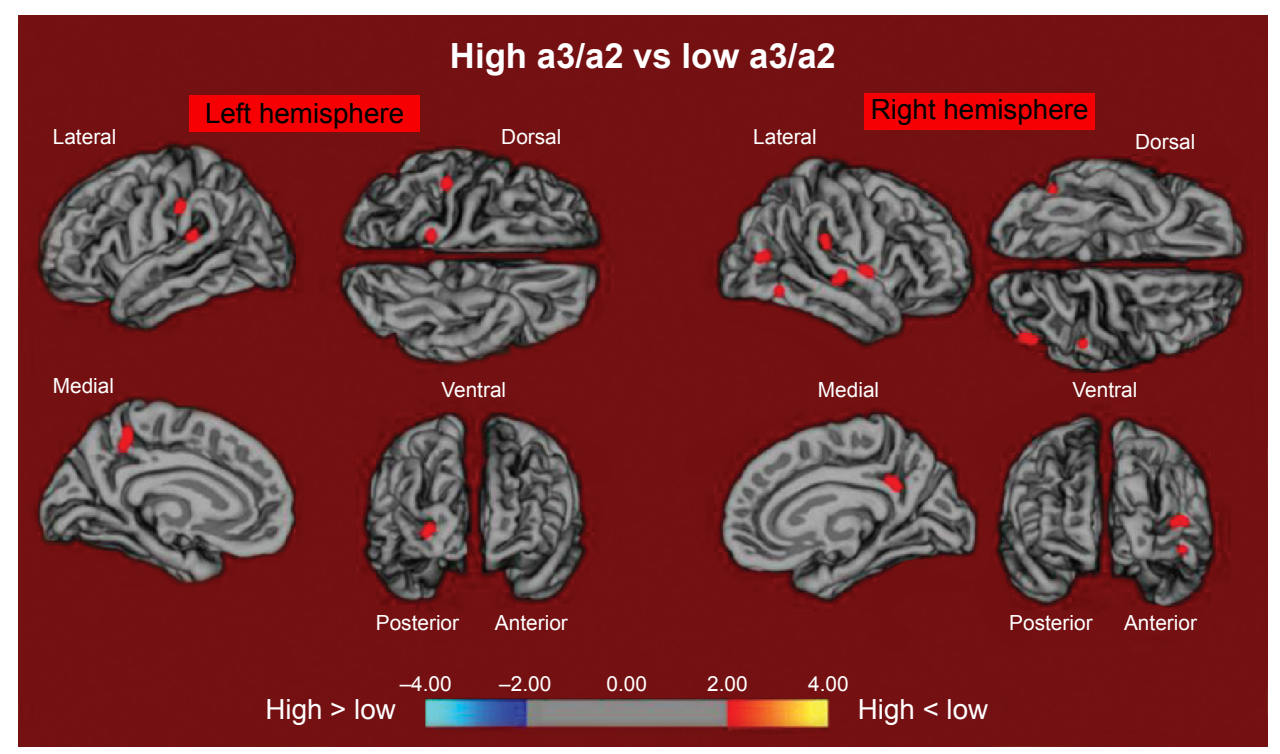

Figure I The red markings represent the brain regions with higher regional cortical thickness in $\mathrm{MCl}$ patients with high a3/a2 ratio as compared to $\mathrm{MCl}$ patients with low a3/a2 ratio $(P<0.0$ I uncorrected $)$.

Notes: The color coding for $P$-values is on a logarithmic scale. Results are presented on the pial cortical surface of the brain: dark gray regions represent sulci and light gray regions represent gyri.

Abbreviations: $\mathrm{MCl}$, mild cognitive impairment; a3, alpha3; a2, alpha2. 


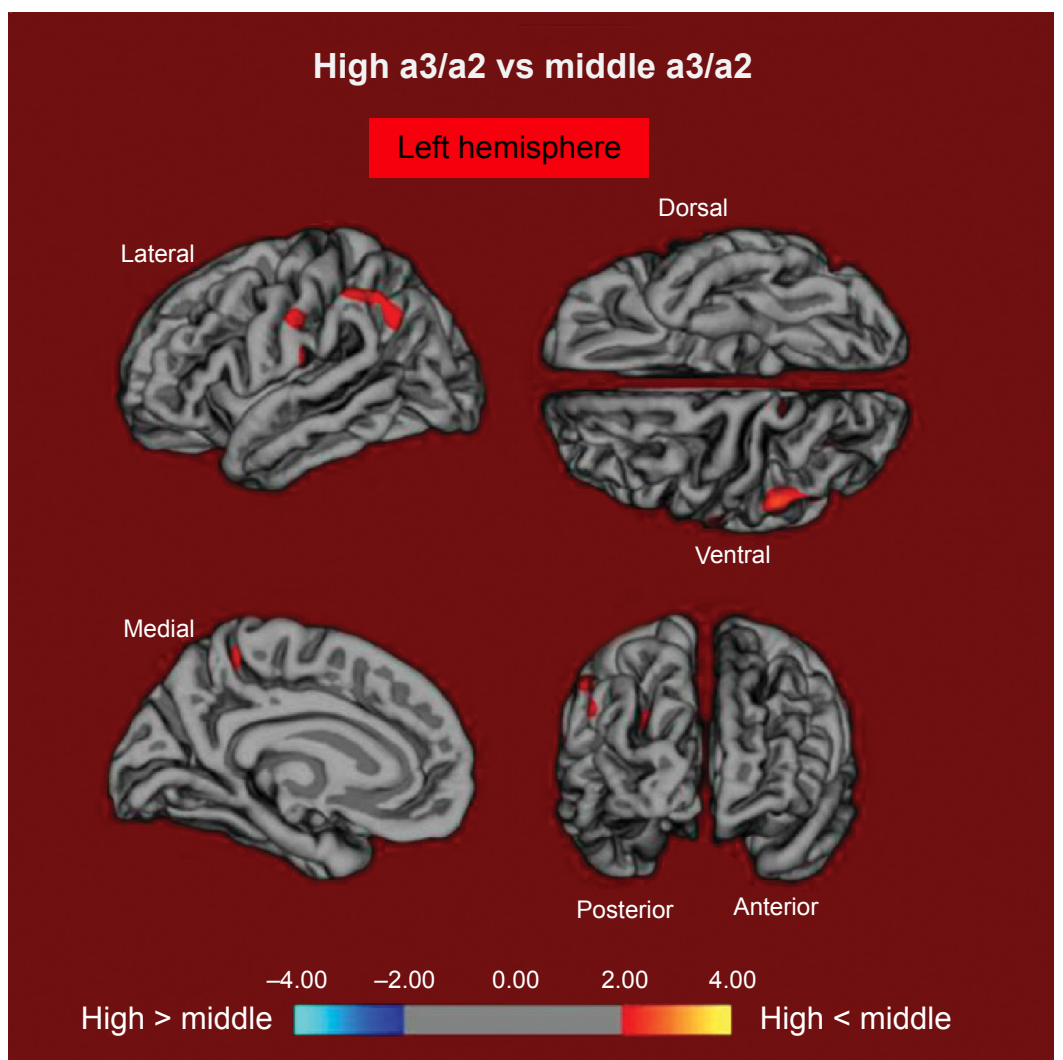

Figure 2 The red markings represent the brain regions with higher regional cortical thickness in $\mathrm{MCl}$ patients with high a3/a2 ratio as compared to $\mathrm{MCl}$ patients with middle a3/a2 ratio $(P<0.01$ uncorrected).

Notes: The color coding for $P$-values is on a logarithmic scale. Results are presented on the pial cortical surface of the brain: dark gray regions represent sulci and light gray regions represent gyri.

Abbreviations: $\mathrm{MCl}$, mild cognitive impairment; a3, alpha3; a2, alpha2.

power ratio, there is a steady pattern to a lower perfusion. Additionally, left HVs were lower for AD in high-hazard patients compared to low-risk patients $(P=0.001)$. In patients who are generally safe to create AD, a huge Pearson's $r$ negative correlation was found between perfusion in the hippocampal complex ROI and theta oscillation $(r=-0.544$; $P=0.044)$. In patients who are at high hazard to create $\mathrm{AD}$, different connections were found. As opposed to patients who are generally safe, we discovered a positive relationship between perfusion in the hippocampal complex ROI and theta band $(r=0.729 ; P=0.005)$ in high-hazard patients, whereas transient ROI corresponded particularly with theta/gamma power ratio $(r=0.736 ; P=0.004)$ in this group. No other huge relationships were found in either group between perfusion

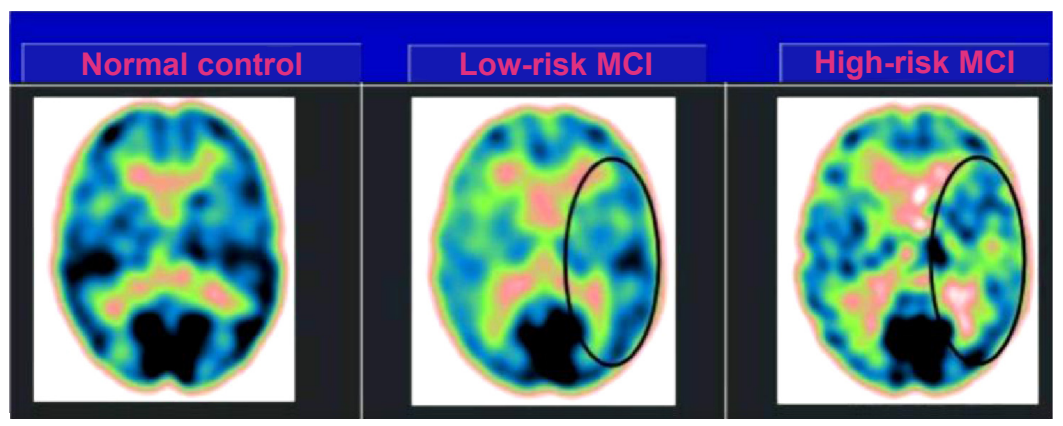

Figure 3 SPECT visual rating.

Notes: The output shows a SPECT visual inspection of glucose uptake metabolism: the black oval denotes an area of mild-to-moderate temporoparietal hypometabolism in one of the 14 low-risk $\mathrm{MCl}$ patients and in one of the 13 high-risk $\mathrm{MCl}$ patients respective to one of the 17 enrolled controls.

Abbreviations: SPECT, single-photon emission computed tomography; $\mathrm{MCl}$, mild cognitive impairment. 


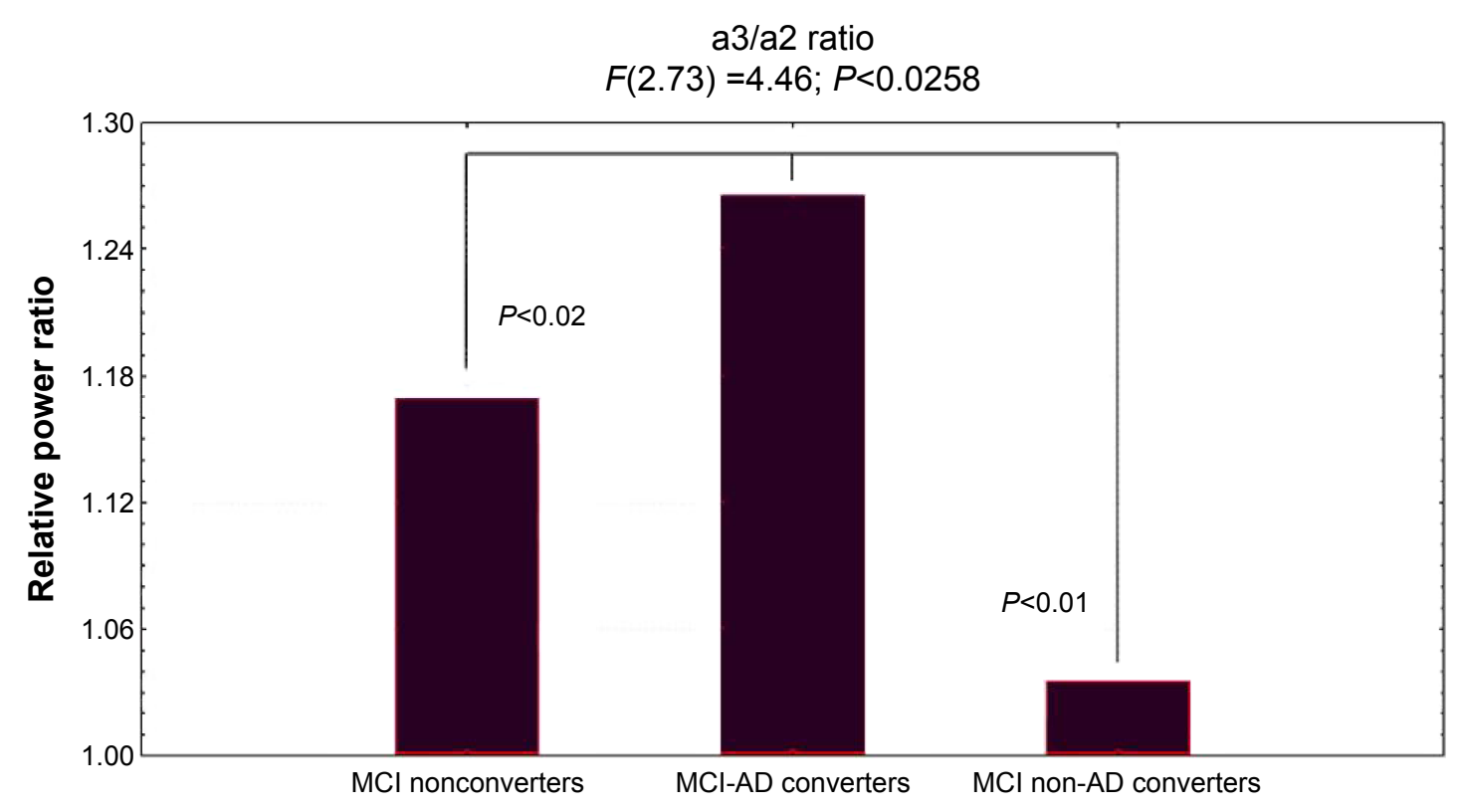

Figure 4 ANOVA results of theta/gamma and a3/a2 relative power ratio.

Note: In the graph, post hoc results are shown.

Abbreviations: ANOVA, analysis of variance; a3, alpha3; a2, alpha2; $\mathrm{MCl}$, mild cognitive impairment; AD, Alzheimer's disease.

ROIs and other EEG rhythms or HVs. Additionally, no noteworthy relationships were found between hippocampal complex ROI and theta frequency band pooling in low- and high-hazard patients together $(r=0.086 ; P=0.671)$.

\section{Follow-up results}

Figure 4 showed ANOVA with significant statistical difference of theta/gamma and $\mathrm{a} 3 / \mathrm{a} 2$ relative power ratio $(F 2,73=3.70, P<0.03$, and $F 2,73=4.46, P<0.02$, respectively). Duncan's post hoc test showed a significant increase $(P<0.01)$ of theta/gamma in both MCI converters group and nonconverters as well as a significant increase of a3/a2 ratio in $\mathrm{MCI}-\mathrm{AD}$ converters with respect to the other groups $(P<0.02)$. In order to strengthen the results, the analysis was also repeated covarying the HV and NPS scores. Significant results were confirmed for both theta/gamma $(F 2,73=2.49$, $P<0.05)$ and a3/a2 ratio $(F 2,73=3.15, P<0.04)$.

The results in discriminant factor analysis show a statistical significant result for the model $(F 30,185=11.16$, $P<0.00001$; Wilks Lambda 0.04). A correct classification of groups was performed in $85 \%$ of cases in the first group, $94 \%$ in the second group, and $86 \%$ in the third group. The mean correct percentage of correct classification was $88.3 \%$. Based on the model structure, the variables accepted, ordered for statistical significance, were theta/gamma frequency ratio $(P<0.0003)$ and a3/a2 frequency ratio $(P<0.03)$. EEG markers, together with the duration of disease, were the most powerful variables in discriminating groups. The canonical analysis shows that the variables accepted were arranged in two discriminant functions (or roots). The two roots were all statistically significant (root1, $P<0.0001 ; \operatorname{root} 2, P<0.001)$. Figure 5 shows scatterplot of canonical scores (the root1 vs root2). The factor loadings of the variables on each discriminant function, as addressed by the factor structure matrix, shows that in root1, theta/gamma relative power ratio has positive $(0.5)$ and a3/a2 relative power ratio has negative $(-0.7)$ correlations, whereas in root 2 , theta/gamma relative power ratio has negative $(-0.6)$ and $\mathrm{a} 3 / \mathrm{a} 2$ relative power ratio has positive (0.8) correlations with the discriminant function. As a consequence, an increase of theta/gamma relative power ratio better identifies the third group and the increase of a3/a2 relative power ratio better identifies the second group.

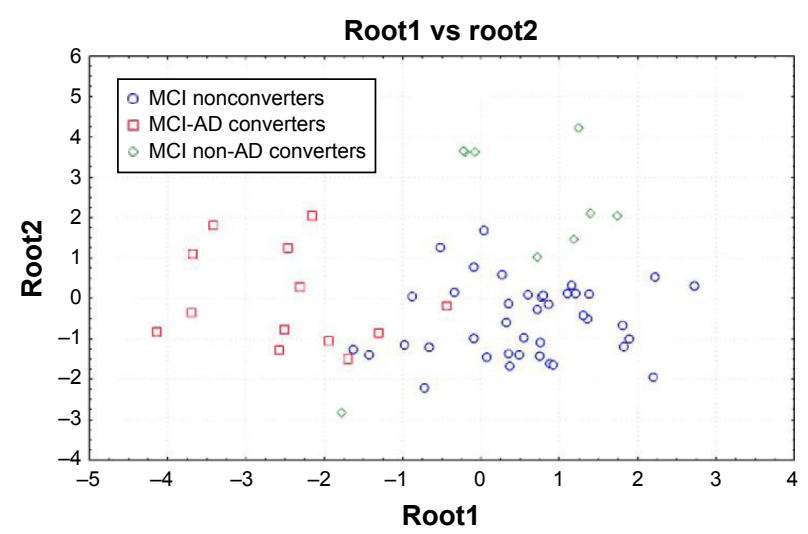

Figure 5 Discriminant factor analysis results: rootl vs root2. Abbreviations: $\mathrm{MCl}$, mild cognitive impairment; $A D$, Alzheimer's disease. 


\section{Discussion Study limitations}

There are a few confinements and provisions in the present study: 1) further studies are expected to affirm our outcome on a bigger sample size; 2) the present results have to be confirmed with the new diagnostic criteria for prodromal AD; 3 ) the example of cortical thickness ought to be researched on the remaining EEG frequency measures; 4) the conservative $P<0.001$ utilized here is not so adequate given that the quantity of correlations and a correction with multiple comparisons test should be more adequate. However, because of the exploratory nature of the study, it is conceivable a tolerant approach keeping in mind the end goal to maintain a strategic distance from to dismiss potentially fascinating results. It stays clear that further studies with less tolerant measurable methodology are required to affirm the results. Of note, the reliability of the outcomes is bolstered by 1) the thorough determination criteria of the subjects, 2) the high measurable edge $(P<0.001)$ considered, and 3$)$ lastly, the substantial size of pixel represented the examination $\left(30 \mathrm{~mm}^{2}\right)$.

\section{EEG markers and cortical atrophy}

The relationship between an EEG marker (the a3/a2 power ratio) and the cortical thickness in subjects with MCI was looked in the present study. The a3/a2 ratio was picked in light of the fact that past work has demonstrated that MCI subjects with higher a3/a2 extent are at noteworthy threat to make AD ${ }^{31-34}$ Our results show that the MCI pack with higher a3/a2 extent has a more vital overall cortical rot than interchange subgroups, along these lines attesting past writing. ${ }^{18,31}$ Additionally, the more unmistakable rot is basic in two specific cerebrum domains: the precuneus and the supramarginal gyrus (a brain district having a spot inside the parietal lobule), in both left and right hemispheres. These results were for the most part expected considering past studies. Most likely, useful and auxiliary adjustments of the precuneus were seen in $\mathrm{MCI},{ }^{73-75}$ and likewise in $\mathrm{AD},{ }^{76-78}$ so that the rot of the precuneus has been seen as a pathognomonic marker prodromal AD. Later studies recommend that specific territories, particularly the precuneus and posterior cingulate together with medial temporal lobe, are exposed to amyloid load in $\mathrm{AD}$ pathology. ${ }^{79,80}$

\section{EEG markers and regional cerebral perfusion}

Our outcomes affirm the results of past studies that have demonstrated that patients with high risk of conversion to
AD have diminished SPECT perfusion in the temporoparietal cortex and parietal lobule. ${ }^{77,78}$ Moreover, our results certify a definitely comprehended association with hippocampal decay. ${ }^{77}$ The present study exhibits an association between cerebral perfusion and theta rhythm. Neverthless, the connection rises just when considering the distinctive groups exclusively utilizing the a3/a2 EEG power ratio. This is affirmed by the finding that when the groups are combined, no relationship could be found. This is the principle part of the study and the particular curiosity of the outcomes. Low levels of hippocampal theta EEG power is maintained in patients at lower risk of $\mathrm{AD}$, who have a steady pattern toward a higher brain local blood perfusion, while in patients at higher risk, with a fundamentally lower cerebral blood perfusion, theta frequency power tends to be greater in the hippocampus. Theta rhythms are for the most part not detected in the remaining EEG recordings.

Nonetheless, a theta force increment is seen over the frontal and transient ranges amid learning and memory undertakings. The theta rhythms that are recorded amid these undertakings are thought to be created by the initiation of the septal-hippocampal framework. The hippocampus has a cholinergic innervation beginning from the basal forebrain, the medial septum, and the vertical limb of the diagonal band of Broca. The synchronized depolarization of hippocampal neurons produces field potentials that have a primary recurrence of 3-12 Hz and are generally known as hippocampal theta rhythm. ${ }^{69,70} \mathrm{~A}$ cholinergic-glutamatergic speculation of $\mathrm{AD}$, in which most indications may be clarified by cholinergic-glutamatergic deficiencies, has been progressed. Neuronal damage may incorporate an excitotoxic part that perhaps adds to the early cholinergic deficiency. This excitotoxic segment may happen, at any rate to a limited extent, at the septal level where the somas of cholinergic neurons are found. This affront may alter septal systems and add to the irregular information processing in $\mathrm{AD}$ brain, including its hyperexcitability states.

\section{Diagnostic implications}

Following 3 years of postliminary, three subgroups were described as converters to $\mathrm{AD}(\mathrm{N}=18)$, converters to non- $\mathrm{AD}$ dementia $(\mathrm{N}=14)$, and nonconverters $(\mathrm{N}=42) \mathrm{MCI}$ to $\mathrm{AD}$ converters. Increase of a3/a2 frequency power ratio was just connected with the change to AD. EEG markers permit a mean right rate of right characterization up to $88.3 \%$. Future forthcoming studies are expected to assess the affectability and specificity of these measures for anticipating an $\mathrm{AD}$ result. ${ }^{31}$ 


\section{Neural networks changes}

From a neurophysiological perspective, the synchronization (or power increment) of EEG alpha oscillations has been connected with the hindrance timing speculation ${ }^{24}$ and with poor data transmission, as indicated by the entropy hypothesis. ${ }^{39,81-104}$ The increments in alpha amplitudes reflect hindrance of cortical mind districts. ${ }^{37,38,105}$ Thus, the entropy hypothesis expressed that synchronization is disadvantageous for putting away data, as it decreases the stream of data. ${ }^{39}$ Entropy is a measure of the lavishness of data encoded in a succession of occasions. Applying this thought to the neural frameworks, it has been demonstrated that the level of information that is encoded in neural systems increases as a part of desynchronization and decreases as a component of synchronized neural networks. ${ }^{90,106,107}$ This theory has been affirmed in clinical studies in patients with memory deficiencies ${ }^{108}$ and in addition amid states where there is minimal subjective handling (eg, epileptic seizures or moderate wave rest). ${ }^{80,109,110}$ As for the cognitive decline because of $\mathrm{AD}$, the run of typical synaptic losses could keep the physiological adaptability of brain neural assemblies, blocking the desynchronizing downstream adjustment of the mind action. As a result, it could be estimated that the disturbance of the cortical system because of degenerative pathology, instigating cortical atrophy, could focus on oversynchronization of the brain oscillatory action. The synchronization condition of the high alpha power could keep the making of a semantic tangible code, and, hence, the roundabout memory follows. ${ }^{111-113}$ Of note, as indicated by the new demonstrative criteria for $\mathrm{AD}$, the estimation of affectability to semantic prompting can effectively separate patients with $\mathrm{AD}$ from sound controls, notwithstanding when patients are compared to controls on MMSE scores or when illness seriousness is extremely mild. Our outcomes are for the most part in accordance with this theory, recommending that an increment in the power of high alpha oscillations mirrors an impairment of data processing..$^{27,28,114-132}$ Of note, such an example of diminished cerebral bloodstream and increased excitability was discovered even preceding the onset of cognitive decline or cortical atrophy. ${ }^{29,30}$

\section{Conclusion}

Increase of EEG upper/low alpha power ratio was related to cortical decay and lower territorial perfusion in the temporoparietal zone in subjects with prodromal AD. The addition in the upper/low alpha power ratio, together with MRI and SPECT, as well as PET-FDG and PET-amyloid biomarkers, could be useful for assessing individuals at high hazard to develop $\mathrm{AD}$ and may be useful in the clinical setting.

\section{Disclosure}

The author reports no conflicts of interest in this work.

\section{References}

1. Dubois B, Feldman HH, Jacova C, et al. Research criteria for the diagnosis of Alzheimer's disease: revising the NINCDS-ADRDA criteria. Lancet Neurol. 2007;6(8):734-746. [Review: Alzheimers Dement. 2011;7(3):270-279].

2. Albert MS, DeKosky ST, Dickson D, et al. The diagnosis of mild cognitive impairment due to Alzheimer's disease: recommendations from the National Institute on Aging-Alzheimer's Association workgroups on diagnostic guidelines for Alzheimer's disease. Alzheimers Dement. 2011;7(3):270-279.

3. Hampel H, Bürger K, Teipel SJ, Bokde AL, Zetterberg H, Blennow K. Core candidate neurochemical and imaging biomarkers of Alzheimer's disease. Alzheimers Dement. 2008;4:38-48.

4. Galluzzi S, Geroldi C, Amicucci G, et al; Translational Outpatient Memory Clinic Working Group. Supporting evidence for using biomarkers in the diagnosis of MCI due to AD. J Neurol. 2013;260(2):640-650.

5. Ma Y, Zhang S, Li J, et al. Predictive accuracy of amyloid imaging for progression from mild cognitive impairment to Alzheimer disease with different lengths of follow-up: a meta-analysis. [Corrected]. Medicine (Baltimore). 2014;93(27):e150. [Review].

6. Leuzy A, Carter SF, Chiotis K, Almkvist O, Wall A, Nordberg A. Concordance and diagnostic accuracy of [11C]PIB PET and cerebrospinal fluid biomarkers in a sample of patients with mild cognitive impairment and Alzheimer's disease. J Alzheimers Dis. 2015;45(4):1077-1088.

7. Gietl AF, Warnock G, Riese F, et al. Regional cerebral blood flow estimated by early PiB uptake is reduced in mild cognitive impairment and associated with age in an amyloid-dependent manner. Neurobiol Aging. 2015;36(4):1619-1628.

8. Choi HJ, Seo EH, Yi D, et al. Amyloid-independent amnestic mild cognitive impairment and serum apolipoprotein A1 levels. Am J Geriatr Psychiatry. Epub 2015 Jun 26.

9. Jiménez-Bonilla JF, Banzo I, De Arcocha-Torres M, et al. Amyloid imaging with 11C-PIB in patients with cognitive impairment in a clinical setting: a visual and semiquantitative analysis. Clin $\mathrm{Nucl} \mathrm{Med}$. Epub 2015 Aug 18.

10. Devanand DP, Mikhno A, Pelton GH, et al. Pittsburgh compound B (11C-PIB) and fluorodeoxyglucose (18 F-FDG) PET in patients with Alzheimer disease, mild cognitive impairment, and healthy controls. J Geriatr Psychiatry Neurol. 2010;23(3):185-198.

11. Palmqvist S, Zetterberg H, Mattsson N, et al; Alzheimer's Disease Neuroimaging Initiative, Swedish BioFINDER Study Group. Detailed comparison of amyloid PET and CSF biomarkers for identifying early Alzheimer disease. Neurology. 2015;85(14):1240-1249.

12. Khan W, Aguilar C, Kiddle SJ, et al; Alzheimer's Disease Neuroimaging Initiative. A subset of cerebrospinal fluid proteins from a multi-analyte panel associated with brain atrophy, disease classification and prediction in Alzheimer's disease. PLoS One. 2015;10(8):e0134368.

13. Bruno D, Grothe MJ, Nierenberg J, et al. The relationship between CSF tau markers, hippocampal volume and delayed primacy performance in cognitively intact elderly individuals. Alzheimers Dement (Amst). 2015;1(1):81-86.

14. Saykin AJ, Shen L, Yao X, et al; Alzheimer's Disease Neuroimaging Initiative. Genetic studies of quantitative $\mathrm{MCI}$ and $\mathrm{AD}$ phenotypes in ADNI: progress, opportunities, and plans. Alzheimers Dement. 2015;11(7): 792-814. [Review].

15. Martínez-Torteya A, Treviño V, Tamez-Peña JG. Improved diagnostic multimodal biomarkers for Alzheimer's disease and mild cognitive impairment. Biomed Res Int. 2015;2015:961314.

16. Perani D, Cerami C, Caminiti SP, et al. Cross-validation of biomarkers for the early differential diagnosis and prognosis of dementia in a clinical setting. Eur J Nucl Med Mol Imaging. Epub 2015 Sep 4.

17. Frisoni GB, Sabattoli F, Lee AD, Dutton RA, Toga AW, Thompson PM. In vivo neuropathology of the hippocampal formation in $\mathrm{AD}$ : a radial mapping MR-based study. Neuroimage. 2006;32(1):104-110. 
18. Frisoni GB, Pievani M, Testa C, et al. The topography of grey matter involvement in early and late onset Alzheimer's disease. Brain. 2007; 130:720-730.

19. Frisoni GB, Ganzola R, Canu E, et al. Mapping local hippocampal changes in Alzheimer's disease and normal ageing with MRI at 3 Tesla. Brain. 2008;131(pt 12):3266-3276.

20. Frisoni GB, Prestia A, Rasser PE, Bonetti M, Thompson PM. In vivo mapping of incremental cortical atrophy from incipient to overt Alzheimer's disease. J Neurol. 2009;256(6):916-924.

21. Frisoni GB. Alzheimer disease: biomarker trajectories across stages of Alzheimer disease. Nat Rev Neurol. 2012;8(6):299-300.

22. van Strien NM, Cappaert NL, Witter MP. The anatomy of memory: an interactive overview of the parahippocampal-hippocampal network. Nat Rev Neurosci. 2009;10(4):272-282.

23. Missonnier P, Herrmann FR, Michon A, Fazio-Costa L, Gold G, Giannakopoulos P. Early disturbances of gamma band dynamics in mild cognitive impairment. J Neural Transm. 2010;117(4):489-498.

24. Steriade M. Grouping of brain rhythms in corticothalamic systems. Neuroscience. 2006;137(4):1087-1106. [Review].

25. Lopes da Silva FH, Vos JE, Mooibroek J, van Rotterdam A. Relative contributions of intracortical and thalamo-cortical processes in the generation of alpha rhythms, revealed by partial coherence analysis. Electroencephalogr Clin Neurophysiol. 1980;50(5-6):449-456.

26. Ingber L, Nunez PL. Neocortical dynamics at multiple scales: EEG standing waves, statistical mechanics, and physical analogs. Math Biosci. 2011;229(2):160-173.

27. Nunez P. Generation of human EEG rhythms by a combination of long and short-range neocortical interactions. Brain Topogr. 1989;1: 199-215.

28. Stam CJ, Montez T, Jones BF, et al. Disturbed fluctuations of resting state EEG synchronization in Alzheimer's disease. Clin Neurophysiol. 2005;116(3):708-715.

29. Moretti DV, Babiloni F, Carducci F, et al. Computerized processing of EEG-EOG-EMG artifacts for multi-centric studies in EEG oscillations and event-related potentials. Int J Psychophysiol. 2003;47(3): 199-216.

30. Moretti Davide V, Babiloni C, Binetti G, et al. Individual analysis of EEG frequency and band power in mild Alzheimer's disease. Neurophysiol Clin. 2004;115:299-308.

31. Moretti DV, Miniussi C, Frisoni G, et al. Vascular damage and EEG markers in subjects with mild cognitive impairment. Neurophysiol Clin. 2007;118:1866-1876.

32. Moretti DV, Miniussi C, Frisoni GB, et al. Hippocampal atrophy and EEG markers in subjects with mild cognitive impairment. Clin $\mathrm{Neu}$ rophysiol. 2007;118(12):2716-2729.

33. Moretti DV, Frisoni GB, Pievani M, et al. Cerebrovascular disease and hippocampal atrophy are differently linked to functional coupling of brain areas: an EEG coherence study in MCI subjects. $J$ Alzheimers Dis. 2008;14(3):285-299.

34. Moretti DV, Frisoni GB, Fracassi C, et al. MCI patients' EEGs show group differences between those who progress and those who do not progress to AD. Neurobiol Aging. 2011;32(4):563-571.

35. Bakkour A, Morris JC, Dickerson BC. The cortical signature of prodromal AD: regional thinning predicts mild AD dementia. Neurology. 2009;72(12):1048-1055.

36. Klimesch W, Doppelmayr M, Hanslmayr S. Upper alpha ERD and absolute power: their meaning for memory performance. Prog Brain Res. 2006;159:151-165.

37. Klimesch W, Sauseng P, Hanslmayr S. EEG alpha oscillations: the inhibition timing hypothesis. Brain Res Rev. 2007;53:63-88.

38. Klimesch W. Evoked alpha and early access to the knowledge system: the P1 inhibition timing hypothesis. Brain Res. 2011;1408:52-71.

39. Shannon CE, Weaver W. The Mathematical Theory of Communication. Urbana, IL: University of Illinois Press; 1949.

40. Folstein MF, Folstein SE, McHugh PR. 'Mini mental state': a practical method for grading the cognitive state of patients for clinician. J Psychiatr Res. 1975;12:189-198.
41. Hughes CP, Berg L, Danziger WL, Cohen LA, Martin RL. A new clinical rating scale for the staging of dementia. Br J Psychiatry. 1982;140: 1225-1230.

42. Rosen WG, Terry RD, Fuld PA, Katzman R, Peck A. Pathological verification of ischemic score in differentiation of dementias. Ann Neurol. 1980;7(5):486-488.

43. Lawton MP, Brodie EM. Assessment of older people: self maintaining and instrumental activity of daily living. J Gerontol. 1969;9:179-186.

44. Petersen RC, Doody R, Kurz A, et al. Current concepts in mild cognitive impairment. Arch Neurol. 2001;58(12):1985-1992.

45. Portet F, Ousset PJ, Visser PJ, et al; MCI Working Group of the European Consortium on Alzheimer's Disease (EADC). Mild cognitive impairment (MCI) in medical practice: a critical review of the concept and new diagnostic procedure. Report of the MCI Working Group of the European Consortium on Alzheimer's disease. J Neurol Neurosurg Psychiatry. 2006;77:714-718.

46. Lezak M, Howieson D, Loring DW. Neuropsychological Assessment. 4th ed. Oxford: University Press; 2004.

47. Radloff LS. The CES-D scale: a self-report depression scale for research in the general population. Appl Psychol Meas. 1977;1:385-401.

48. Moretti DV. Mild Cognitive Impairment: Structural, Metabolical, and Neurophysiological Evidence of a Novel EEG Biomarker. Front Neurol. 2015 Jul 6;6:152. doi: 10.3389/fneur.2015.00152

49. Klimesch W. EEG-alpha rhythms and memory processes. Int J Psychophysiol. 1997;26:319-340.

50. Klimesch W. EEG alpha and theta oscillations reflect cognitive and memory performance: a review and analysis. Brain Res Rev. 1999;29: 169-195.

51. Kaplan AY. The problem of segmental description of human electroencephalogram. Human Physiol. 1999;25:107-114.

52. Cohen BA, Sances A. Stationarity of the human electroencephalogram. Med Biol Eng Comput. 1977;15:513-518.

53. Kawabata N. Test of statistical stability of the electroencephalogram. Biol Cybern. 1976;22:235-238.

54. McEwen JA, Anderson GB. Modeling the stationarity and gaussianity of spontaneous electroencephalographic activity. IEEE Trans Biomed Eng. 1975;22:361-369.

55. Kipiński L, König R, Sielużycki C, Kordecki W. Application of modern tests for stationarity to single-trial MEG data: transferring powerful statistical tools from econometrics to neuroscience. Biol Cybern. 2011; 105(3-4):183-195.

56. Moretti DV, Fracassi C, Pievani M, et al. Increase of theta/gamma ratio is associated with memory impairment. Clin Neurophysiol. 2009; 120(2):295-303.

57. Moretti DV, Pievani M, Fracassi C, et al. Increase of theta/gamma and alpha3/alpha2 ratio is associated with amygdalo-hippocampal complex atrophy. J Alzheimers Dis. 2009;17(2):349-357.

58. Moretti DV, Pievani M, Geroldi C, et al. Increasing of hippocampal atrophy and cerebrovascular damage is differently associated with functional cortical coupling in MCI patients. Alzheimer Dis Assoc Disord. 2009;23(4):323-332.

59. Cabeza R. Hemispheric asymmetry reduction in older adults: the HAROLD model. Psychol Aging. 2002;17(1):85-100. [Review].

60. Balsters JH, O’Connell RG, Galli A, et al. Changes in resting connectivity with age: a simultaneous electroencephalogram and functional magnetic resonance imaging investigation. Neurobiol Aging. 2013;34(9): 2194-2207.

61. Watson P, Conroy A, Moran G, Duncan S. Retrospective study of sensitivity and specificity of EEG in the elderly compared with younger age groups. Epilepsy Behav. 2012;25(3):408-411.

62. Tenke CE, Kayser J, Miller L, et al. Neuronal generators of posterior EEG alpha reflect individual differences in prioritizing personal spirituality. Biol Psychol. 2013;94(2):426-432.

63. Grandy TH, Werkle-Bergner M, Chicherio C, Schmiedek F, Lövdén M, Lindenberger U. Peak individual alpha frequency qualifies as a stable neurophysiological trait marker in healthy younger and older adults. Psychophysiology. 2013;50(6):570-582. 
64. Grandy TH, Werkle-Bergner M, Chicherio C, Lövdén M, Schmiedek F, Lindenberger $\mathrm{U}$. Individual alpha peak frequency is related to latent factors of general cognitive abilities. Neuroimage. 2013;79:10-18.

65. Bekhtereva V, Sander C, Forschack N, Olbrich S, Hegerl U, Müller MM. Effects of EEG-vigilance regulation patterns on early perceptual processes in human visual cortex. Clin Neurophysiol. 2014;125(1): 98-107.

66. Ségonne F, Dale AM, Busa E, et al. A hybrid approach to the skull stripping problem in MRI. Neuroimage. 2004;22(3):1060-1075.

67. Fischl B, Dale AM. Measuring the thickness of the human cerebral cortex using magnetic resonance images. Proc Natl Acad Sci U S A. 2000;97:11044-11049.

68. Han X, Jovicich J, Salat D, et al. Reliability of MRI-derived measurements of human cerebral cortical thickness: the effects of field strength, scanner upgrade and manufacturer. Neuroimage. 2006;32(1): 180-194.

69. Gronenschild EH, Habets P, Jacobs HI, et al. The effects of FreeSurfer version, workstation type, and Macintosh operating system version on anatomical volume and cortical thickness measurements. PLoS One. 2012;7(6):e38234.

70. DeCarli C, Fletcher E, Ramey V, Harvey D, Jagust WJ. Anatomical mapping of white matter hyperintensities (WMH): exploring the relationships between periventricular WMH, deep WMH, and total WMH burden. Stroke. 2005;36:50-55.

71. Pennanen C, Testa C, Laasko MP, et al. A voxel based morphometry study on mild cognitive impairment. J Neurol Neurosurg Psychiatry. 2005;76:11-14.

72. Markesbery WR, Schmitt RA, Kryscio RJ, Davis D, Smith C, Wekstein D. Neuropathologic substrate of mild cognitive impairment. Arch Neurol. 2006;63:38-46.

73. McKhann GM, Knopman DS, Chertkow H, et al. The diagnosis of dementia due to Alzheimer's disease: recommendations from the national institute on aging-Alzheimer's association workgroups on diagnostic guidelines for Alzheimer's disease. Alzheimers Dement. 2011;7: 263-269.

74. Sperling RA, Aisen PS, Beckett LA, et al. Toward defining the preclinical stages of Alzheimer's disease: recommendations from the National Institute on Aging-Alzheimer's Association workgroups on diagnostic guidelines for Alzheimer's disease. Alzheimers Dement. 2011;7(3):280-292.

75. Caroli A, Testa C, Geroldi C, et al. Brain perfusion correlates of medial temporal lobe atrophy and white matter hyperintensities in mild cognitive impairment. J Neurol. 2007;254(8):1000-1008.

76. Matsuda $\mathrm{H}$. The role of neuroimaging in mild cognitive impairment. Neuropathology. 2007;27:570-577.

77. Petrella JR, Wang L, Krishnan S, et al. Cortical deactivation in mild cognitive impairment: high-field-strength functional MR imaging. Radiology. 2007;245:224-235.

78. Pihlajamaki M, Jauhiainen AM, Soininen H. Structural and functional MRI in mild cognitive impairment. Curr Alzheimer Res. 2009;6: 179-185.

79. Dickerson BC, Sperling RA. Large-scale functional brain network abnormalities in Alzheimer's disease: insights from functional neuroimaging. Behav Neurol. 2009;21:63-75.

80. Ryu SY, Kwon MJ, Lee SB, et al. Measurement of precuneal and hippocampal volumes using magnetic resonance volumetry in Alzheimer's disease. J Clin Neurol. 2010;6:196-203.

81. Sperling RA, Dickerson BC, Pihlajamaki M, et al. Functional alterations in memory networks in early Alzheimer's disease. Neuromolecular Med. 2010;12:27-43.

82. de Haan W, Mott K, van Straaten EC, Scheltens P, Stam CJ. Activity dependent degeneration explains hub vulnerability in Alzheimer's disease. PLoS Comput Biol. 2012;8(8):e1002582.

83. Pievani M, de Haan W, Wu T, Seeley WW, Frisoni GB. Functional network disruption in the degenerative dementias. Lancet Neurol. 2011;10: 829-843.
84. Chatwal JP, Sperling RA. Functional MRI of mnemonic networks across the spectrum of normal aging, mild cognitive impairment, and Alzheimer's disease. J Alzheimers Dis. 2012;31(0):S155-S167.

85. Jones DT, Machulda MM, Vemuri P, et al. Age-related changes in the default mode network are more advanced in Alzheimer disease. Neurology. 2011;77(16):1524-1531

86. Brier MR, Thomas JB, Snyder AZ, et al. Loss of intranetwork and internetwork resting state functional connections with Alzheimer's disease progression. J Neurosci. 2012;32(26):8890-8899.

87. Palop JJ, Mucke L. Synaptic depression and aberrant excitatory network activity in Alzheimer's disease: two faces of the same coin? Neuromolecular Med. 2010;12(1):48-55.

88. Stam CJ, van der Made Y, Pijnenburg YA, Scheltens P. EEG synchronization in mild cognitive impairment and Alzheimer's disease. Acta Neurol Scand. 2003;108(2):90-96. [a. Neuroimage. 2012;59(4):3548-3562].

89. Bhattacharya BS, Coyle D, Maguire LP. Alpha and theta rhythm abnormality in Alzheimer's disease: a study using a computational model. Adv Exp Med Biol. 2011;718:57-73.

90. Rossini PM, Buscema M, Capriotti M, et al. Is it possible to automatically distinguish resting EEG data of normal elderly vs mild cognitive impairment subjects with high degree of accuracy? Clin Neurophysiol. 2008;119(7):1534-1545.

91. Wu X, Li R, Fleisher AS, et al. Altered default mode network connectivity in Alzheimer's disease - a resting functional MRI and Bayesian network study. Hum Brain Mapp. 2011;32(11):1868-1881.

92. Wonderlick JS, Ziegler DA, Hosseini-Varnamkhasti P, et al. Reliability of MRI-derived cortical and subcortical morphometric measures: effects of pulse sequence, voxel geometry, and parallel imaging. Neuroimage. 2009;44(4):1324-1333.

93. Zhang S, Li CS. Functional connectivity mapping of the human precuneus by resting state fMRI. Neuroimage. 2012;59(4):3548-3562.

94. Morbelli S, Drzezga A, Perneczky R, et al. Resting metabolic connectivity in prodromal Alzheimer's disease. A European Alzheimer Disease Consortium (EADC) project. Neurobiol Aging. 2012;33(11): 2533-2550.

95. Ghaem O, MelletE, Crivello F, et al. Mental navigation along memorized routes activates the hippocampus, precuneus, and insula. Neuroreport. 1997;8:739-744.

96. Leichnetz GR. Connections of the medial posterior parietal cortex (area 7m) in the monkey. Anat Rec. 2001;263:215-236.

97. Cavanna AE, Trimble MR. The precuneus: a review of its functional anatomy and behavioural correlates. Brain. 2006;129:564-583.

98. Wenderoth N, Debaere F, Sunaert S, Swinnen SP. The role of anterior cingulate cortex and precuneus in the coordination of motor behaviour. Eur J Neurosci. 2005;22:235-246.

99. Klimesch W, Schimke H, Doppelmayr M, Ripper B, Schwaiger J, Pfurtscheller G. Event-related desynchronization (ERD) and the Dm effect: does alpha desynchronization during encoding predict late recall performance? Int J Psychophysiol. 1996;24:47-60.

100. Klimesch W, Doppelmayr M, Stadler W, Pöllhuber D, Sauseng P, Röhm D. Episodic retrieval is reflected by a process specific increase in human electroencephalographic theta activity. Neurosci Lett. 2001;302:49-52.

101. Fries P, Reynolds JH, Rorie AE, Desimone R. Modulation of oscillatory neuronal synchronization by selective visual attention. Science. 2001;291:1560-1563.

102. Kilner JM, Mattout J, Henson R, Friston KJ. Hemodynamic correlates of EEG: a heuristic. Neuroimage. 2005;28:280-286.

103. Wyart $\mathrm{V}$, Tallon-Baudry $\mathrm{C}$. Neural dissociation between visual awareness and spatial attention. J Neurosci. 2008;28:2667-2679.

104. Spitzer B, Hanslmayr S, Opitz B, Mecklinger A, Bäuml K-H. Oscillatory correlates of retrieval-induced forgetting in recognition memory. J Cogn Neurosci. 2009;21:976-990.

105. Staudigl T, Hanslmayr S, Bäuml K-HT. Theta oscillations reflect the dynamics of interference in episodic memory retrieval. $J$ Neurosci. 2010;30:11356-11362. 
106. Hanslmayr S, Staudigl T, Aslan A, Bäuml K-H. Theta oscillations predict the detrimental effects of memory retrieval. Cogn Affect Behav Neurosci. 2010;10:329-338.

107. Hanslmayr S, Staudigl T, Fellner MC. Oscillatory power decreases and long-term memory: the information via desynchronization hypothesis. Front Hum Neurosci. 2012;6:74.

108. Jensen O, Mazaheri A. Shaping functional architecture by oscillatory alpha activity: gating by inhibition. Front Hum Neurosci. 2010;4:186. doi:10.3389/fnhum.2010.00186.

109. Norman KA. How hippocampus and cortex contribute to recognition memory: revisiting the complementary learning systems model. Hippocampus. 2010;20:1217-1227.

110. Schneidman E, Puchalla JL, Segev R, Harris RA, Bialek W, Berry MJ. Synergy from silence in a combinatorial neural code. $J$ Neurosci 2011;31:15732-15741.

111. Kurimoto R, Ishii R, Canuet L, et al. Induced oscillatory responses during the Sternberg's visual memory task in patients with Alzheimer's disease and mild cognitive impairment. Neuroimage. 2012;59: 4132-4140.

112. Goard M, Dan Y. Basal forebrain activation enhances cortical coding of natural scenes. Nat Neurosci. 2009;12:1444-1449.

113. Chalk M, Herrero JL, Gieselmann MA, Delicato LS, Gotthardt S, Thiele A. Attention reduces stimulus-driven gamma frequency oscillations and spike field coherence in V1. Neuron. 2010;66:114-125.

114. Barlow HB. The coding of sensory messages. In: Thorpe WH, Zangwill OL, editors. Current Problems in Animal Behaviour. Cambridge, UK: Cambridge University Press; 1961:331-360.

115. Bialek W, Rieke F, de Ruytervan Steveninck RR, Warland D. Reading a neural code. Science. 1991;252:1854-1857.

116. Hanslmayr S, Spitzer B, Bäuml K-H. Brain oscillations dissociate between semantic and non semantic encoding of episodic memories. Cereb Cortex. 2009;19:1631-1640.

117. Craik FIM. Levels of processing: past, present and future? Memory. 2002;10:305-318.

118. Moretti DV, Pievani M, Geroldi C, et al. EEG markers discriminate among different subgroup of patients with mild cognitive impairment. Am J Alzheimers Dis Other Demen. 2010;25(1):58-73.

119. Moretti DV, Frisoni GB, Pievani M, et al. Brain vascular damage of cholinergic pathways and E. E. G. markers in mild cognitive impairment. J Alzheimers Dis. 2008;15(3):357-372.

120. Moretti DV, Frisoni GB, Binetti G, Zanetti O. Anatomical substrate and scalp EEG markers are correlated in subjects with cognitive impairment and Alzheimer's disease. Front Psychiatry. 2011;1(152):1-9.

121. Moretti DV, Prestia A, Fracassi C, et al. Volumetric differences in mapped hippocampal regions correlate with increase of high alpha rhythm in Alzheimer's disease. Int J Alzheimers Dis. 2011;2011: 208-218.
122. Moretti DV, Paternicò D, Binetti G, Zanetti O, Frisoni GB. EEG markers are associated to gray matter changes in thalamus and basal ganglia in subjects with mild cognitive impairment. Neuroimage. 2012;60(1):489-496.

123. Moretti DV, Prestia A, Fracassi C, Binetti G, Zanetti O, Frisoni GB. Specific EEG changes associated with atrophy of hippocampus in subjects with mild cognitive impairment and Alzheimer's disease. Int J Alzheimers Dis. 2012;2012:253153.

124. Moretti DV, Zanetti O, Binetti G, Frisoni GB. Quantitative EEG markers in mild cognitive impairment: degenerative versus vascular brain impairment. Int J Alzheimers Dis. 2012;2012:917537.

125. Moretti DV, Paternicò D, Binetti G, Zanetti O, Frisoni GB. Analysis of grey matter in thalamus and basal ganglia based on EEG alpha3/ alpha2 frequency ratio reveals specific changes in subjects with mild cognitive impairment. ASN Neuro. 2012;4(7):e00103.

126. Moretti DV, Paternico’ D, Binetti G, Zanetti O, Frisoni GB. Relationship between EEG Alpha3/Alpha2 ration and the nuclues accumbens in subjects with mild cognitive impairment. J Neurol Neurophysiol. 2013;4(2):1-6.

127. Moretti DV, Paternicò D, Binetti G, Zanetti O, Frisoni GB. Theta/ gamma frequency ratio is associated to grey matter changes in basal ganglia in subjects with mild cognitive impairment. J Radiol Diagn Imaging. 2013;1:10-18.

128. Moretti DV, Paternicò D, Binetti G, Zanetti O, Frisoni GB. Temporoparietal brain network impairment is related To EEG ALPHA3/ ALPHA2 power ratio in prodromal alzheimer's disease. J Neurol Neurophysiol. 2013;4(160):1-9.

129. Moretti DV, Paternicò D, Binetti G, Zanetti O, Frisoni GB. EEG upper/ low alpha frequency power ratio relates to temporo-parietal brain atrophy and memory performances in mild cognitive impairment. Front Aging Neurosci. 2013;5:63.

130. Moretti DV, Prestia A, Binetti G, Zanetti O, Frisoni GB. Increase of theta frequency is associated with reduction in regional cerebral blood flow only in subjects with mild cognitive impairment with higher upper alpha/low alpha EEG frequency power ratio. Front Behav Neurosci. 2013;7:188.

131. Moretti DV, Prestia A, Binetti G, Zanetti O, Frisoni GB. Correlation between regional cerebral blood flow and EEG upper/low alpha frequency power ratio in mild cognitive impairment. J Radiol Diagn Imaging. 2013;1:49-59.

132. Moretti DV, Paternicò D, Binetti G, Zanetti O, Frisoni GB. Electroencephalographic upper/low alpha frequency power ratio relates to cortex thinning in mild cognitive impairment. Neurodegener Dis. 2014;14(1) $18-30$.
Neuropsychiatric Disease and Treatment

\section{Publish your work in this journal}

Neuropsychiatric Disease and Treatment is an international, peerreviewed journal of clinical therapeutics and pharmacology focusing on concise rapid reporting of clinical or pre-clinical studies on a range of neuropsychiatric and neurological disorders. This journa is indexed on PubMed Central, the 'PsycINFO' database and CAS,

\section{Dovepress}

and is the official journal of The International Neuropsychiatric Association (INA). The manuscript management system is completely online and includes a very quick and fair peer-review system, which is all easy to use. Visit http://www.dovepress.com/testimonials.php to read real quotes from published authors. 